\title{
HUBUNGAN KARAKTERISTIK INDIVIDU DAN PENGAWASAN K3 DENGAN UNSAFE ACTION TENAGA KERJA BONGKAR MUAT
}

\author{
Datuh Inayah Dibyaguna Suryanto*, Noeroel Widajati** \\ *,**Departemen Keselamatan dan Kesehatan Kerja, Fakultas Kesehatan Masyarakat \\ Universitas Airlangga, Surabaya, Jawa Timur, Indonesia \\ Alamat Korespondensi: \\ Datuh Inayah Dibyaguna Suryanto \\ Email: datuhinayah@yahoo.com
}

\begin{abstract}
An unsafe action is a problematic behavior by a worker that deviates from workplace safety protocols or is not in accordance with workplace risk procedures. Accidents (80-85\%) are caused by omission labor who demonstrate low compliance to the occupational safety and health in the workplace. The purpose of this research is to analyze the correlations for two sets of parameters related to unsafe loading-unloading labor practices in PT Pelabuhan Indonesia III Cabang Tanjung Perak individual characteristic and occupational safety and health supervision. A quantitive study with a cross sectional approach was conducted. In this study, primary data were obtained from questionnaires and observations in the workplace. Secondary data were obtained from the documents available on the PT Pelabuhan Indonesia III Cabang Tanjung Perak. Study respondents consisted of the loading-unloading workers in PT Pelabuhan Indonesia III Cabang Tanjung Perak. Respondents were obtained from simple random sampling technique, and 59 respondents were enrolled. This study analyzed individual characteristics and occupational safety and health supervision. Data were analyzed by using the Pearson's correlation coefficient pearson with a linear significance of 0.05. Study results indicated that unsafe labor actions by labor occurred in the medium and heavy categories. The Pearson's correlation coefficient indicated that unsafe actions correlated with age and occupational safety and health supervision, while insignificant variables related to unsafe actions included working time and level of education. Training-associated occupational safety and health also required enhanced knowledge about workplace dangers and unsafe actions at work. Especially to labor loading unloading whose aged 31-40 years old and had elementary school.
\end{abstract}

Keywords: unsafe action, individual characteristic, occupational safety and health supervision

\begin{abstract}
ABSTRAK
Unsafe action merupakan perilaku tenaga kerja yang menyimpang dari prinsip keselamatan atau tidak sesuai dengan prosedur kerja yang berisiko untuk timbulnya masalah. Kecelakaan kerja $80-85 \%$ disebabkan oleh kelalaian tenaga kerja yang secara tidak langsung merupakan dampak dari tenaga kerja yang memiliki tingkat kepatuhan rendah dalam penerapan K3 di tempat kerja. Tujuan dari penelitian ini adalah untuk menganalisis hubungan antara karakteristik individu dan pengawasan K3 dengan unsafe action tenaga kerja bongkar muat di PT Pelabuhan Indonesia III Cabang Tanjung Perak. Penelitian ini merupakan penelitian kuantitatif dengan pendekatan cross sectional. Penelitian ini data primer diperoleh dari kuesioner dan observasi di tempat kerja. Data sekunder diperoleh dari dokumen yang tersedia di PT Pelabuhan Indonesia III Cabang Tanjung Perak. Responden penelitian merupakan tenaga kerja bongkar muat. Cara pengambilan sampel menggunakan teknik simple random sampling dan didapatkan responden sebanyak 59 responden. Variabel yang diteliti meliputi karakteristik individu, pengawasan K3 dan unsafe action. Analisis data dalam penelitian ini menggunakan uji statistik korelasi linear pearson dengan tingkat signifikansi 0,05 . Hasil penelitian ini menunjukkan bahwa unsafe action yang dilakukan tenaga kerja tergolong sedang dan berat. Uji statistik korelasi linear pearson menunjukkan bahwa terdapat hubungan antara unsafe action dengan usia dan pengawasan $\mathrm{K} 3$, sedangkan variabel yang
\end{abstract}


tidak signifikan dengan unsafe action adalah masa kerja, tingkat pendidikan. Pelatihan terkait K3 juga diperlukan guna meningkatkan pengetahuan tenaga kerja mengenai bahaya dan unsafe action di tempat kerja, terutama kepada tenaga kerja bongkar muat yang berusia 31-40 tahun dan berpendidikan SD.

Kata kunci: unsafe action, karakteristik individu, pengawasan K3

\section{PENDAHULUAN}

Menurut Suma'mur (2009), faktor lingkungan dan faktor manusia dapat menyebabkan kecelakaan kerja. Faktor lingkungan antara lain kebijakan atau peraturan, peralatan kerja, kondisi area kerja dan prosedur kerja mengenai pelaksanaan keselamatan dan kesehatan kerja (K3). Faktor manusia berupa perilaku atau kebiasaan kerja yang tidak aman (unsafe action). Unsafe action yang sering dijumpai di tempat kerja antara lain tidak memakai alat pelindung diri dan tidak mematuhi prosedur kerja, seperti menjalankan peralatan atau mesin tanpa wewenang, mengabaikan peringatan dan keamanan, serta. Penelitian yang dilakukan oleh Palin (2012), menghasilkan 87,5\% kecelakaan kerja di percetakan terjadi akibat tenaga kerja tidak menjalankan program keselamatan dan kesehatan kerja yaitu penggunaan alat pelindung diri saat bekerja. Penelitian Salawati (2009), menggambarkan 90\% kecelakaan kerja sering terjadi pada tenaga kerja disebabkan oleh unsafe action tenaga kerja, sedangkan $10 \%$ sisanya disebabkan unsafe condition .

Pada laporan Badan Pembinaan Konstruksi dan Sumber Daya Manusia (BPKSDM), Dinas Tenagakerjaan Umum pada tahun 2006, menjelaskan beberapa faktor penyebab terjadinya kecelakaan kerja baik yang telah menimbulkan korban jiwa maupun luka-luka antara lain dikarenakan oleh penggunaan metode pelaksanaan yang kurang tepat, pelaksanaan pengawasan kurang optimal, belum melaksanakan ketentuan dan peraturan yang menyangkut keselamatan dan kesehatan kerja dan kurang disiplinnya para tenaga kerja di dalam mematuhi program keselamatan dan kesehatan kerja (BPKSDM, 2006). Beberapa kasus tersebut menunjukkan bahwa masih banyak tenaga kerja yang tidak patuh dalam menjalankan program keselamatan dan kesehatan kerja. Kecelakaan kerja dapat diakibatkan oleh perilaku ketidakpatuhan tersebut. Upaya atau tindakan yang tepat dapat dilakukan oleh perusahaan setelah mengetahui berbagai penyebab yang mengakibatkan terjadinya kecelakaan kerja.

PT Pelabuhan Indonesia III atau yang sering disebut dengan PT Pelindo III adalah salah satu perusahaan BUMN yang bergerak di bidang jasa pelayanan operator terminal pelabuhan. PT Pelabuhan Indonesia III memiliki cabang di beberapa wilayah di Indonesia, salah satunya adalah Pelabuhan Tanjung Perak di Surabaya. Usaha yang dilakukan PT Pelabuhan Indonesia III Cabang Tanjung Perak meliputi pelayanan dan penyediaan jasa terminal petikemas, curah kering, curah cair, dan Ro-ro (roll on-roll off) juga menyediakan layanan bongkar muat. Pertumbuhan bongkar muat barang khususnya di Pelabuhan. Aktivitas di Pelabuhan Tanjung Perak semakin lama semakin meningkat, kegiatan bongkar muat ini menggunakan alat bantu bongkar muat antara lain CC, HMC, RTG, FL dan ada yang masih menggunakan tenaga manusia. Salah satu yang berperan penting dalam kelancaran proses bongkar muat barang di Pelabuhan Tanjung Perak adalah tenaga kerja bongkar muat. Data kecelakaan kerja tenaga kerja bongkar muat, termasuk yang meninggal dunia menurun dari tahun 2004 terjadi sebanyak 29 pekerja $(4,11 \%)$, tahun 2005 sebanyak 44 pekerja $(5,6 \%)$, tahun 2006 sebanyak 1 pekerja $(2,21 \%)$, tahun 2007 sebanyak 20 pekerja (2,56\%) (Rais dkk, 2009). 
Berbagai macam faktor yang dapat menyebabkan terjadinya kecelakaan di tempat kerja, seperti pengawasan terhadap pekerja, peralatan dan perlengkapan kerja yang sudah tidak layak pakai, dan juga pemakaian alat pelindung diri. Ketika kegiatan bongkar muat berlangsung, dilakukan pengawasan oleh petugas safety PT Pelabuhan Indonesia III Cabang Tanjung Perak terhadap perusahaan bongkar muat dan tenaga kerja bongkar muat, di mana mereka harus mematuhi peraturan yang telah diterapkan di wilayah kerja seperti pemakaian alat pelindung diri, rambu keselamatan dan kesehatan kerja, dan lain-lain. Penerapan peraturan tersebut tidak terlepas dari perilaku tenaga kerja bongkar muat. Unsafe action dan unsafe condition berpotensi menimbulkan kecelakaan kerja dan menyebabkan kegiatan bongkar muat menjadi terhenti, serta dapat menimbulkan kerugian bagi perusahaan. Upaya pencegahan kecelakaan kerja akibat unsafe action tenaga kerja bongkar muat perlu dilakukan, dalam hal ini adalah adanya kesadaran akan pentingnya keselamatan dalam bekerja. Perlu adanya penelitian untuk mengetahui hubungan faktor penyebab dasar dengan unsafe action. Berdasarkan hal tersebut, peneliti tertarik untuk menganalisis hubungan antara karakteristik individu dan pengawasan keselamatan dan kesehatan kerja dengan unsafe action berdasarkan konsep ILCI di PT Pelabuhan Indonesia III Cabang Tanjung Perak Surabaya.

Tujuan penelitian ini adalah untuk mengidentifikasi karakteristik individu tenaga kerja bongkar muat, pengawasan keselamatan dan kesehatan kerja di PT Pelabuhan Indonesia III Cabang Tanjung Perak, dan unsafe action tenaga kerja bongkar muat, menganalisis hubungan antara karakteristik individu dengan unsafe action tenaga kerja bongkar muat, serta menganalisis hubungan antara pengawasan keselamatan dan kesehatan kerja dengan unsafe action tenaga kerja bongkar muat di terminal jamrud PT Pelabuhan Indonesia III Cabang Tanjung Perak.

\section{METODE PENELITIAN}

Penelitian ini menggunakan penelitian observasional yang bersifat analitik. Penelitian ini menggunakan pendekatan cross sectional. Tenaga kerja bongkar muat berjumlah 59 orang. Penelitian ini dilakukan di PT Pelabuhan Indonesia III Cabang Tanjung Perak. Waktu penelitian dilaksanakan sejak pembuatan proposal di Bulan Maret 2016 sampai dengan Januari 2017. Variabel independen dalam penelitian ini adalah karakteristik individu dan pengawasan keselamatan dan kesehatan kerja, sedangkan variabel dependen adalah unsafe action. Data primer dalam penelitian ini menggunakan kuesioner dan observasi. Data sekunder diperoleh dari PT Pelabuhan Indonesia III Cabang Tanjung Perak. Teknik analisis data menggunakan uji statistik komputer.

\section{HASIL}

Berdasarkan Undang-Undang No. 17 Tahun 2008 tentang Penyelenggaraan Pelabuhan Umum, "PT Pelabuhan Indonesia III bertanggung jawab atas keselamatan pelayaran, penyelenggaraan pelabuhan, angkutan perairan dan lingkungan maritim". Status PT Pelabuhan Indonesia III berubah dari regulator menjadi operator pelabuhan, dengan begitu secara otomatis bisnis PT Pelabuhan Indonesia III berubah dari port operator menjadi terminal operator. PT Pelabuhan Indonesia III memiliki wewenang dan tugas untuk mengelola 43 pelabuhan yang tersebar di tujuh Provinsi yaitu Kalimantan Selatan, Kalimantan Tengah, Jawa Tengah, Jawa Timur, Bali, Nusa Tenggara Barat dan Nusa Tenggara Timur, serta memiliki tujuh anak perusahaan. Pelabuhan Tanjung Perak merupakan salah satu pintu gerbang Indonesia dan distribusi barang dari dan ke Kawasan Timur Indonesia. PT Pelabuhan Indonesia III Cabang Tanjung Perak memiliki kantor pusat di Surabaya. PT Pelabuhan Indonesia III Cabang Tanjung Perak dalam mengusahakan dan menyediakan jasa kepelabuhan agar dapat menunjang 
kelancaran angkutan laut, memiliki bidang usaha meliputi: pelayanan jasa dan/atau penyediaan curah kering, curah cair, terminal peti kemas, dan Ro-Ro; pelayanan dan/ atau penyediaan jasa bongkar muat barang; pelayanan dan/atau penyediaan jasa dermaga sebagai penunjang kegiatan bongkar muat peti kemas dan barang; penyediaan jasa dan/ atau pelayanan dermaga untuk berlabuh; pelayanan dan/atau penyediaan fasilitas naik turun penumpang dan kendaraan; pelayanan dan/atau penyediaan tempat penimbunan barang, alat bongkar muat dan gudang serta peralatan kepelabuhan; penyediaan dan/ atau pelayanan pengisian bahan bakar dan; pelayanan dan/atau penyediaan konsolidasi barang dan pusat distribusi; penyediaan dan/ atau pelayanan jasa penundaan kapal.

PT Pelabuhan Indonesia III Cabang Tanjung Perak Surabaya menerapkan kebijakan Mutu Keselamatan dan Kesehatan Kerja Lingkungan (MK3L). Kebijakan MK3L sesuai dengan visi dan misi perusahaan serta kebijakan MK3L ini berlaku di lingkungan PT Pelabuhan Indonesia III Cabang Tanjung Perak Surabaya. Dalam Kebijakan MK3L PT Pelabuhan Indonesia III bertekad untuk senantiasa mengutamakan peningkatan kualitas pelayanan serta perlindungan terhadap keselamatan dan kesehatan kerja setiap operasionalnya, dengan senantiasa peduli terhadap lingkungan hidup melalui pemeliharaan lingkungan kerja pelabuhan yang berwawasan lingkungan (eco port) serta berkomitmen menaati peraturan perundangan maupun persyaratan lingkungan lain yang terkait dengan aspek lingkungan, melakukan pencegahan terhadap pencemaran, serta melakukan peningkatan berkelanjutan sistem manajemen MK3L.

Terminal Jamrud terdiri dari 3 (tiga) bagian dengan peruntukan berbeda, yaitu: Jamrud Utara, Jamrud Selatan dan Jamrud Barat. Terminal Jamrud Utara diperuntukkan bagi kegiatan embarkasi dan debarkasi penumpang domestik dan kapal pesiar (kade 0-400), operasi bongkar muat kargo umum internasional (kade 400-800), dan curah kering internasional (kade 800-1200). Terminal ini memiliki luas $136,106 \mathrm{~m}^{2}$ dengan panjang dermaga $1,200 \mathrm{~m}^{2}$ dan kedalaman kolam -10 mlws. Terminal Jamrud Selatan diperuntukkan bagi curah kering domestik (kade 0-120) dan kargo umum domestik (kade 120-800). Terminal ini memiliki luas $86,252 \mathrm{~m}^{2}$ dengan panjang dermaga $800 \mathrm{~m}^{2}$ dan kedalaman kolam -7 mlws. Selain itu, terminal Jamrud Barat diperuntukkan bagi curah kering internasional (kade 0-210). Terminal ini memiliki luas $3,255 \mathrm{~m}^{2}$ dengan panjang dermaga $210 \mathrm{~m}^{2}$ dan kedalaman kolam -6 mlws. Dalam hal bongkar muat barang, tingkat produktivitas aktual untuk operasi bongkar muat komoditas barang adalah 6000 ton/kapal/hari.

Usia responden berkisar antara 24 tahun sampai dengan 56 tahun. Usia responden kisaran 21-30 tahun berjumlah 4 orang 6,8\%), usia responden kisaran 31 40 tahun sebanyak 47 orang $(79,7 \%)$, usia responden kisaran 41-50 tahun berjumlah 5 orang $(8,5 \%)$, usia responden lebih dari 50 tahun berjumlah 3 orang $(5,1 \%)$. Diketahui bahwa, variasi usia responden didominasi oleh responden dalam kisaran usia 31 tahun hingga 40 tahun. Masa kerja responden di Terminal Jamrud berkisar antara tiga tahun sampai dengan 28 tahun. Responden yang memiliki masa kerja kurang dari lima tahun berjumlah 3 orang $(5,1 \%)$, responden yang memiliki masa kerja lima sampai dengan sepuluh tahun berjumlah 11 orang $(18,6 \%)$ dan responden yang memiliki masa kerja lebih dari 10 tahun berjumlah 45 orang (76,3\%). Diketahui bahwa variasi masa kerja responden didominasi oleh responden dalam kisaran masa kerja lebih dari 10 tahun. Responden yang memiliki tingkat pendidikan SD sebanyak 40 orang $(67,8 \%)$, SMP berjumlah 13 orang (22\%), dan SMA berjumlah 6 orang (10,2\%). Diketahui bahwa tingkat pendidikan responden didominasi oleh tenaga kerja yang memiliki tingkat pendidikan SD.

Pengawasan K3 dilakukan oleh petugas safety melalui kegiatan safety patrol. Kegiatan 
Datuh I.D. Suryanto dan Noeroel Widajati, Hubungan Karakteristik Individu dan ... 55

Tabel 1. Hubungan antara Usia dengan Unsafe Action TKBM PT Pelabuhan Indonesia III Cabang Tanjung Perak Tahun 2016

\begin{tabular}{|c|c|c|c|c|c|c|c|c|c|c|}
\hline \multirow{3}{*}{ Usia } & \multicolumn{8}{|c|}{ Unsafe Action } & \multirow{3}{*}{$\begin{array}{c}p \\
\text { value }\end{array}$} & \multirow{3}{*}{$r$} \\
\hline & \multicolumn{2}{|c|}{ Ringan } & \multicolumn{2}{|c|}{ Sedang } & \multicolumn{2}{|c|}{ Berat } & \multicolumn{2}{|c|}{ Total } & & \\
\hline & $\mathbf{n}$ & $\%$ & $\mathbf{n}$ & $\%$ & $\mathrm{n}$ & $\%$ & n & $\%$ & & \\
\hline 21-30 tahun & 0 & 0 & 2 & 3,4 & 2 & 3,4 & 4 & 100 & & \\
\hline 31-40 tahun & 0 & 0 & 27 & 45,8 & 20 & 33,9 & 47 & 100 & 0007 & 310 \\
\hline $41-50$ tahun & 1 & 1,7 & 4 & 6,8 & 0 & 0 & 5 & 100 & 0.017 & -.010 \\
\hline$>50$ tahun & 0 & 0 & 3 & 5,1 & 0 & 0 & 3 & 100 & & \\
\hline
\end{tabular}

Tabel 2. Hubungan antara Masa Kerja dengan Unsafe Action TKBM PT Pelabuhan Indonesia III Cabang Tanjung Perak Tahun 2016

\begin{tabular}{|c|c|c|c|c|c|c|c|c|c|c|}
\hline \multirow{3}{*}{ Masa Kerja } & \multicolumn{8}{|c|}{ Unsafe Action } & \multirow{3}{*}{$\begin{array}{c}p \\
\text { value }\end{array}$} & \multirow{3}{*}{$r$} \\
\hline & \multicolumn{2}{|c|}{ Ringan } & \multicolumn{2}{|c|}{ Sedang } & \multicolumn{2}{|c|}{ Berat } & \multicolumn{2}{|c|}{ Total } & & \\
\hline & $\mathbf{n}$ & $\%$ & $\mathbf{n}$ & $\%$ & n & $\%$ & n & $\%$ & & \\
\hline$<5$ tahun & 0 & 0 & 1 & 1,7 & 2 & 3,4 & 3 & 100 & & \\
\hline 5-10 tahun & 0 & 0 & 6 & 10,2 & 5 & 8,5 & 11 & 100 & 0.183 & -.176 \\
\hline$>10$ tahun & 1 & 1,7 & 29 & 49,2 & 15 & 25,4 & 45 & 100 & & \\
\hline
\end{tabular}

Tabel 3. Hubungan antara Tingkat Pendidikan dengan Unsafe Action TKBM PT Pelabuhan Indonesia III Cabang Tanjung Perak Tahun 2016

\begin{tabular}{|c|c|c|c|c|c|c|c|c|c|c|}
\hline \multirow{3}{*}{$\begin{array}{c}\text { Tingkat } \\
\text { Pendidikan }\end{array}$} & \multicolumn{8}{|c|}{ Unsafe Action } & \multirow{3}{*}{$\underset{\text { value }}{p}$} & \multirow{3}{*}{$r$} \\
\hline & \multicolumn{2}{|c|}{ Ringan } & \multicolumn{2}{|c|}{ Sedang } & \multicolumn{2}{|c|}{ Berat } & \multicolumn{2}{|c|}{ Total } & & \\
\hline & $\mathbf{n}$ & $\%$ & $\mathbf{n}$ & $\%$ & $\mathbf{n}$ & $\%$ & $\mathbf{n}$ & $\%$ & & \\
\hline $\mathrm{SD}$ & 1 & 1,7 & 27 & 45,8 & 12 & 20,3 & 40 & 100 & & \\
\hline SMP & 0 & 0 & 7 & 11,9 & 6 & 10,2 & 13 & 100 & 0.054 & 0.252 \\
\hline SMA & 0 & 0 & 2 & 3,4 & 4 & 6,8 & 6 & 100 & & \\
\hline
\end{tabular}

Tabel 4. Hubungan antara Pengawasan K3 dengan Unsafe Action TKBM PT Pelabuhan Indonesia III Cabang Tanjung Perak Tahun 2016

\begin{tabular}{|c|c|c|c|c|c|c|c|c|c|c|}
\hline \multirow{3}{*}{$\begin{array}{c}\text { Pengawasan } \\
\text { K3 }\end{array}$} & \multicolumn{8}{|c|}{ Unsafe Action } & \multirow{3}{*}{$\begin{array}{c}p \\
\text { value }\end{array}$} & \multirow{3}{*}{$r$} \\
\hline & \multicolumn{2}{|c|}{ Ringan } & \multicolumn{2}{|c|}{ Sedang } & \multicolumn{2}{|c|}{ Berat } & \multicolumn{2}{|c|}{ Total } & & \\
\hline & $\mathbf{n}$ & $\%$ & $\mathbf{n}$ & $\%$ & n & $\%$ & n & $\%$ & & \\
\hline Baik & 1 & 1,7 & 9 & 15,3 & 0 & 0 & 10 & 100 & & \\
\hline Cukup baik & 0 & 0 & 27 & 45,8 & 21 & 35,6 & 48 & 100 & 0.001 & -.426 \\
\hline Kurang baik & 0 & 0 & 0 & 0 & 1 & 1,7 & 1 & 100 & & \\
\hline
\end{tabular}


safety patrol telah terjadwal dan dilakukan setiap hari pada setiap terminal yang ada. Jadwal safety patrol pada terminal jamrud yaitu satu kali dalam satu minggu. Tingkat pengawasan keselamatan dan kesehatan kerja dalam penelitian ini dikategorikan menjadi tiga, yaitu kurang baik, cukup baik dan baik. Distribusi frekuensi persepsi pengawasan keselamatan dan kesehatan kerja di Terminal Jamrud terdapat seorang responden $(1,7 \%)$ yang menyatakan bahwa pengawasan $\mathrm{K} 3$ kurang baik, sebanyak 48 orang $(81,4 \%)$ menyatakan cukup baik dan 10 orang (16,9\%) menyatakan baik. Dapat diketahui sebagian besar responden berpendapat bahwa variasi tingkat pengawasan $\mathrm{K} 3$ dapat dikatakan cukup baik. Data unsafe action didapatkan dari kuesioner peneliti yang terdiri dari 20 pertanyaan mengenai unsafe action. Unsafe action dalam penelitian ini dibedakan menjadi unsafe action kategori ringan, sedang dan berat. Terdapat seorang responden $(1,7 \%)$ melakukan unsafe action kategori ringan, unsafe action kategori sedang sebanyak 36 orang (61\%) dan unsafe action kategori berat sebanyak 22 orang (37,3\%). Hasil penelitian menunjukkan bahwa tingkat unsafe action terbesar yang dilakukan tenaga kerja bongkar muat adalah unsafe action kategori sedang.

Tabel 1 menunjukkan bahwa usia antara 31 sampai dengan 40 tahun cenderung melakukan unsafe action kategori sedang dan berat. Ada hubungan yang signifikan antara usia responden dengan unsafe action. Pada Tabel 2 dapat dilihat bahwa sebagian besar responden yang melakukan unsafe action berat memiliki masa kerja lebih dari 10 tahun. Pada Tabel 3 menunjukkan semakin tinggi tingkat pendidikan responden semakin tinggi unsafe action kategori ringan. Tabel 4 menunjukkan semakin baik tingkat pengawasan maka semakin sedikit unsafe action kategori berat.

\section{PEMBAHASAN}

Unsafe action dapat diartikan sebagai tindakan atau perilaku tenaga kerja yang tidak sesuai dengan prosedur kerja atau menyimpang dari prinsip keselamatan kerja. Unsafe action dapat berisiko untuk timbulnya suatu masalah (Sirait, 2011). Unsafe action merupakan kesalahan manusia dalam mengambil sikap atau tindakan. Human Factors Analysis and Classification System (HFACS) mengklasifikasikan unsafe action menjadi pelanggaran (violations) dan kesalahan (errors). Pelanggaran mengacu pada niat untuk tidak menghiraukan aturan atau petunjuk yang telah ditetapkan untuk melaksanakan tugas. Kesalahan merupakan hasil dari suatu kegiatan fisik dan mental individu yang gagal mencapai sesuatu yang diinginkan (Pranicasari, 2014). Klasifikasi kesalahan manusia dapat disebabkan oleh kesalahan karena lupa, tidak tahu, tidak mampu dan karena kurang motivasi (Sirait, 2011). Kecelakaan kerja tenaga kerja bongkar muat dari tahun 2014 sampai dengan tahun 2016 terdapat enam kasus kecelakaan kerja yang tercatat. Unsafe action yang sering dijumpai di terminal jamrud antara lain tenaga kerja bongkar muat tidak memakai alat pelindung diri lengkap saat bekerja, merokok, beristirahat di bawah alat berat atau di samping armada transportasi, tidur di sekitar gudang, duduk atau istirahat di tepi dermaga, tenaga kerja menggunakan peralatan yang tidak sesuai, terdapat juga tenaga kerja bongkar muat yang menggunakan peralatan tanpa wewenang ataupun Surat Izin Operasional (SIO).

Usia dalam penelitian ini diartikan rentang usia yang dimiliki responden sejak lahir hingga penelitian ini dilakukan. kinerja seseorang seringkali dihubungkan dengan usia dikarenakan kinerja seseorang yang semakin menurun dengan meningkatnya usia. Keterampilan fisik seseorang seperti kecepatan, kekuatan, kelenturan, dan koordinasi akan semakin menurun dengan bertambahnya usia seseorang. Adapun kapasitas fisik seperti penglihatan, pendengaran dan kecepatan reaksi akan menurun pada usia lebih dari 30 tahun (Suma'mur, 2009). 
Diketahui bahwa variasi usia responden didominasi oleh responden yang berusia dalam kisaran 31 tahun sampai dengan usia 40 tahun. Responden yang berusia antara 31 sampai dengan 40 tahun cenderung melakukan unsafe action. Banyaknya tenaga kerja bongkar muat rentang usia antara 3140 tahun yang melakukan unsafe action kategori berat dapat disebabkan karena sebagian besar responden yang bekerja di Terminal Jamrud berada pada kelompok usia tersebut, sehingga kemungkinan lebih banyak tenaga kerja melakukan unsafe action jika dibandingkan dengan kelompok usia yang lain. Responden yang berusia lebih dari rentang usia tersebut, yaitu responden yang berusia lebih dari 40 tahun cenderung melakukan unsafe action kategori ringan. Tenaga kerja dengan usia yang lebih muda cenderung lebih ceroboh dalam menjaga keselamatan diri jika dibandingkan dengan usia yang lebih tua.

Emosi yang tidak stabil dan anggapan remeh terhadap bahaya dan risiko bahaya yang ada di tempat kerja dapat membuat tenaga kerja usia muda kurang berhatihati dalam bekerja. Bertambahnya usia responden dapat menunjukkan pola berpikir yang lebih rasional, memiliki kemampuan untuk mengontrol emosi dan sifat lainnya yang menunjukkan kematangan secara intelektual dan psikologis. Berdasarkan diskusi dengan pengawas, tenaga kerja di usia muda memiliki semangat tinggi dikarenakan tenaga kerja tersebut masih sebagai tenaga kerja baru dan ingin mendapatkan hasil kerja yang maksimal guna menghasilkan penghasilan yang lebih banyak, mereka sering memaksakan diri dalam bekerja dan mengabaikan safety procedure.

Usia dan unsafe action memiliki hubungan yang signifikan. Keeratan korelasi yang diperoleh yaitu korelasi cukup. Walaupun memiliki keeratan hubungan cukup, tetap diperlukan sebagai upaya preventif untuk memperkecil unsafe action. Upaya tersebut dapat dengan lebih meningkatkan pengawasan. Hasil penelitian ini sesuai dengan penelitian yang dilakukan oleh Shiddiq dkk (2013), yang menjelaskan bahwa adanya hubungan signifikan antara usia dengan unsafe action. Penelitian Setyawati (2010), juga menyatakan adanya hubungan antara usia dan unsafe action, di mana semakin bertambahnya usia tenaga kerja, semakin tinggi pula pemahaman tentang unsafe action sehingga tenaga kerja cenderung untuk melakukan safe action selama bekerja.

Hal tersebut didukung oleh penelitian Sulfikar (2015), menjelaskan bahwa semakin tua usia tenaga kerja bongkar muat maka semakin baik perilaku keselamatannya. Hal tersebut sesuai dengan pernyataan Suma'mur (1996), yaitu kewaspadaan terhadap suatu kecelakaan bertambah baik sesuai dengan usia, masa kerja di perusahaan dan lamanya bekerja di tempat kerja yang bersangkutan. Perlu diketahui bahwa usia adalah faktor personal yang dimiliki oleh individu dan dapat memengaruhi unsafe action walaupun terdapat faktor lain yang dapat memengaruhi terjadinya unsafe action.

Masa kerja adalah lamanya responden bekerja sebagai tenaga kerja bongkar muat yang dihitung dari awal masuk kerja sampai dengan penelitian ini dilakukan. Menurut pendapat Robbins (2001), masa kerja bisa diekspresikan sebagai suatu pengalaman kerja. Masa kerja berkaitan erat dengan pengalaman yang didapat seseorang selama menjalankan pekerjaannya, di mana pekerja yang berpengalaman dipandang lebih mampu melaksanakan dan memahami pekerjaannya. Menurut Suma'mur (2009), pengalaman seseorang untuk mengenal bahaya di tempat kerja akan semakin membaik seiring dengan bertambahnya usia dan masa kerja, sehingga pada pekerja lama akan lebih mengenal titik-titik bahaya pada tempat kerja mereka yang pada akhirnya dapat meminimalkan terjadinya kesalahan (error) yang dapat mengakibatkan kecelakaan. Berdasarkan hasil kuesioner yang terdapat pada Tabel 2, 
dapat diketahui responden yang melakukan unsafe action kategori sedang dan berat memiliki masa kerja lebih dari 10 tahun. Maka semakin lama seseorang bekerja semakin tinggi unsafe action dalam kategori berat. Berdasarkan uji statistik korelasi pearson, pada Tabel 2 diketahui tidak ada hubungan yang signifikan antara masa kerja responden dengan unsafe action.

Sebuah penelitian yang dilakukan oleh Sholehudin (2013), menerangkan bertambahnya masa kerja mengakibatkan semakin rendah persentase unsafe action. Koefisien korelasi dalam penelitian ini menunjukkan adanya hubungan yang cukup antara masa kerja dengan unsafe action. Hal itu bisa terjadi karena pada kondisi di tempat kerja berbeda dengan teori. Para tenaga kerja bongkar muat yang merasa bahwa pekerjaannya memiliki risiko kerja yang tinggi cenderung akan memilih untuk berhenti atau keluar dari perusahaan dan mencari pekerjaan yang dirasa lebih aman, mengingat bahwa profesi sebagai tenaga kerja bongkar muat tidak memiliki jenjang karir, sehingga adanya keluar masuknya pekerja cukup tinggi.

Tenaga kerja bongkar muat yang tidak keluar masuk perusahaan, tidak mempunyai alasan untuk keluar dari perusahaan kecuali karena mengalami kecelakaan kerja atau karena bertambahnya usia (Winarsunu, 2008). Hasil penelitian ini didukung dengan adanya penelitian Listyandini (2013), serta dalam penelitian Pratiwi (2013), yang menyatakan bahwa tidak terdapat hubungan yang bermakna antara masa kerja dengan perilaku tidak aman. Penelitian Sulfikar (2015), menyebutkan bahwa tidak ada hubungan bermakna antara masa kerja dan unsafe action. Banyaknya pengalaman kerja dan lamanya masa kerja bukan merupakan faktor penentu bahwa tenaga kerja tersebut dapat berperilaku aman selama bekerja di tempat kerja. Kecelakaan kerja bukan hanya disebabkan oleh satu faktor saja, namun terdapat beberapa faktor yang memengaruhi. Upaya untuk peningkatan motivasi kerja pada tenaga kerja yang memiliki masa kerja lebih lama dapat meminimalisir unsafe action.

Pendidikan menjadi salah satu faktor yang menjadi dasar untuk memberikan motivasi terhadap tindakan atau perilaku individu dalam pengalaman belajarnya. Jadi dapat dikatakan bahwa tingkat pendidikan tenaga kerja dapat menentukan luasnya pengetahuan serta bagaimana tenaga kerja tersebut bersikap dan berperilaku di tempat kerja. Tenaga kerja bongkar muat yang mempunyai tingkat pendidikan rendah akan mengalami kesusahan dalam memahami suatu inovasi baru sehingga mempersulit untuk mencapai perubahan seperti yang diharapkan. Dalam penelitian ini, pendidikan yang dimaksud adalah pendidikan formal yang diperoleh di sekolah, yaitu SD, SMP, SMA, serta pendidikan tinggi. Berdasarkan teori yang ada, dapat dikatakan bahwa tingkat pendidikan tenaga kerja yang lebih tinggi dapat memengaruhi perilaku tenaga kerja untuk menjadi lebih baik dan lebih bijak dalam bertindak. Kecelakaan kerja memiliki berbagai penyebab, salah satu penyebabnya adalah unsafe action.

Terjadinya unsafe action dapat disebabkan karena kurangnya pendidikan dan pengetahuan mengenai unsafe action. Menurut Anizar (2009), salah satu faktor personal yang dapat menyebabkan kecelakaan adalah tingkat pendidikan. Pendidikan tenaga kerja merupakan salah satu hal yang harus diperhatikan dan penting untuk meningkatkan kesadaran mengenai pentingnya keselamatan dan kesehatan kerja (Permana, 2014).

Kurangnya pendidikan dapat menjadi penyebab kesalahan dalam kurangnya pengalaman, kurangnya keterampilan, dan pemahaman suatu perintah, serta salah mengartikan standart operational procedure sehingga dapat mengakibatkan kesalahan. Berdasarkan Tabel 3 diketahui bahwa semakin tinggi tingkat pendidikan responden semakin tinggi unsafe action kategori ringan. Sebaliknya semakin rendah tingkat 
pendidikan responden maka semakin tinggi untuk unsafe action kategori berat. Hasil penelitian diperoleh tidak ada hubungan yang signifikan antara tingkat pendidikan responden dengan unsafe action.

Hal ini tidak sejalan dengan teori yang mengatakan bahwa pendidikan seseorang tenaga kerja memengaruhi pola pikir seseorang dalam menghadapi pekerjaannya yang dipercayakan kepadanya, termasuk cara pencegahan kecelakaan maupun menghindari kecelakaan kerja saat melakukan pekerjaannya, selain itu tingkat penyerapan terhadap pelatihan yang diberikan dipengaruhi oleh pendidikan dalam rangka melaksanakan pekerjaan dan keselamatan kerja (Permana, 2014).

Penelitian ini memiliki hasil yang sama dengan penelitian yang dilaksanakan oleh Listyandini (2013), menyebutkan bahwa tidak ada hubungan yang bermakna antara tingkat pendidikan dengan unsafe action. Penelitian ini juga didukung oleh penelitian Sulfikar (2015), dengan hasil tidak ada hubungan yang bermakna antara tingkat pendidikan responden dengan safety behavior. Fakta tersebut tidak menjamin semakin tinggi tingkat pendidikan formal responden, semakin baik perilakunya. Hal ini terjadi karena kenyataannya di tempat kerja sebagian besar tenaga kerja bongkar muat mempunyai tingkat pendidikan terakhir yang beragam dan mempunyai keterampilan atau skill dalam proses bongkar muat yang berbeda pula, mengingat bahwa kegiatan atau proses bongkar muat adalah jenis pekerjaan yang lebih membutuhkan keterampilan, kekuatan fisik dan skill dibandingkan dengan kemampuan pendidikan formal. Selain itu, tidak adanya hubungan antara unsafe action dengan masa kerja kemungkinan dapat dikarenakan tidak adanya perbedaan jenis pekerjaan berdasarkan tingkat pendidikan yang dimiliki tenaga kerja bongkar muat, sehingga potensi bahaya yang diperoleh sama. Dapat disimpulkan bahwa faktor pendidikan belum tentu menentukan unsafe action yang dilakukan oleh tenaga kerja bongkar muat. Kondisi tersebut kemungkinan juga disebabkan oleh pendidikan yang telah diperoleh oleh pekerja di sekolah formal masih belum banyak membahas mengenai K3. Tidak ada salahnya apabila perusahaan memberikan pelatihan mengenai unsafe action agar tenaga kerja bongkar muat lebih waspada dan mencegah adanya kecelakaan.

Tabel 4 dapat diketahui bahwa semakin baik tingkat pengawasan $\mathrm{K} 3$ maka semakin sedikit peluang untuk unsafe action kategori berat. Diperoleh bahwa ada hubungan antara pengawasan K3 dengan unsafe action. Nilai koefisien korelasi menunjukkan bahwa korelasi antara pengawasan dengan unsafe action yaitu cukup. Pada Tabel 4 diketahui bahwa ada hubungan yang signifikan antara pengawasan K3 dengan unsafe action. Nilai korelasi menunjukkan koefisien korelasi antara pengawasan dengan unsafe action adalah cukup. Hal itu menunjukkan bahwa semakin rendah pengawasan responden maka semakin berat kategori unsafe action yang dilakukan, sebaliknya jika pengawasan semakin baik maka responden melakukan unsafe action kategori ringan. Hasil penelitian ini tidak sama dengan penelitian Pratiwi (2009), yang menyatakan tidak ada hubungan antara pengawasan dengan unsafe action. Pengawasan adalah kegiatan manajerial perusahaan yang mengupayakan agar pekerjaan terlaksana sesuai dengan rencana yang ditetapkan dan hasil yang diharapkan. Pengawasan dapat dikatakan berhasil apabila manajer atau supervisor melakukan pemeriksaan, pengecekan, inspeksi pengendalian dan mengatur serta mencegah kemungkinan kejadian yang mungkin terjadi (Sarwono, 1997)

Pengawasan dilakukan oleh petugas safety dan sudah terjadwal pelaksanaannya. Pengawasan dilakukan setiap hari sesuai jadwal terminal yang sudah ditentukan dengan kata lain setiap satu minggu sekali di masing-masing terminal. Pada saat observasi, dijumpai tenaga kerja bongkar 
muat menggunakan alat pelindung diri, namun penggunaan alat pelindung diri masih tidak benar. Hasil penelitian menunjukkan sebagian besar tenaga kerja bongkar muat tidak menggunakan alat pelindung diri berupa safety shoes, masker, helm, dan rompi.

Tenaga kerja merasa bahwa mereka bekerja tidak dalam waktu yang lama sehingga mereka tidak memerlukan penggunaan alat pelindung diri. Banyak pula ditemukan tenaga kerja bongkar muat yang menggunakan alat pelindung diri apabila ada pengawas melakukan inspeksi di tempat kerja mereka, bahkan terdapat beberapa tenaga kerja yang menggunakan alat pelindung diri apabila ditegur oleh pengawas. Hal tersebut dapat disebabkan oleh beragam faktor seperti kesadaran diri tentang pentingnya $\mathrm{K} 3$ masih kurang, pengawasan belum optimal, serta sarana prasarana yang disediakan masih kurang dan sebagainya.

Pengawasan dilakukan oleh petugas safety yang sudah terjadwal pelaksanaannya. Pengawasan dilakukan setiap hari sesuai jadwal terminal yang sudah ditentukan dengan kata lain setiap satu minggu sekali di masing-masing terminal. Apabila hal tersebut terus-menerus dilakukan oleh tenaga kerja, maka semakin banyak tenaga kerja yang melakukan unsafe action yang dapat membahayakan diri mereka sendiri dan orang lain di sekitarnya. Peraturan dan sosialisasi yang telah diadakan mengenai pentingnya penerapan $\mathrm{K} 3$ di tempat kerja dan unsafe action, tetapi kesadaran tenaga kerja mengenai keselamatan dalam bekerja masih kurang.

Menurut Geller (2001), tingkat kepatuhan pekerja dalam berperilaku dapat ditingkatkan dengan cara intralisasi, yaitu pekerja melakukan sesuatu atas dasar memahami, mengetahui pentingnya melakukan suatu tindakan tersebut dan penerapannya dalam suatu keadaan. Berdasarkan hasil observasi dan wawancara dengan pengawas $\mathrm{K} 3$, tenaga kerja yang melakukan unsafe action diketahui adalah tenaga kerja yang telah lama bekerja di area kerja tersebut atau telah lama bekerja di pelabuhan, sehingga banyak tenaga kerja yang cenderung meremehkan teguran karena dampak bagi mereka cenderung ringan, yaitu hanya berupa teguran.

Berdasarkan pendapat dari beberapa responden, adanya pengawasan dari pihak perusahaan saat mereka bekerja dapat memengaruhi perilaku bekerja menjadi lebih baik. Jika dihubungkan antara pengawasan K3 dan unsafe action. Halimah (2010), menjelaskan bahwa pengawasan bertujuan untuk memastikan kegiatan kerja yang dilakukan berjalan sesuai rencana. Bila fungsi pengawasan tidak dilaksanakan dengan baik, maka akan menimbulkan penyebab dasar yaitu terjadinya suatu insiden yang dapat mengganggu kegiatan perusahaan (Birds dan Germain, 1992). Namun, tidak menjamin bahwa adanya pengawasan maka tindakan pekerja selalu aman. Namun, hal tersebut bukan berarti pengawasan tidak diperlukan untuk mengubah perilaku pekerja, justru sebaliknya pelaksanaan pengawasan yang rutin akan mendorong motivasi pekerja untuk berperilaku aman. Berdasarkan teori, tenaga kerja selalu bekerja dengan baik, benar, memakai APD dan berperilaku aman dapat ditingkatkan dengan adanya pengawasan. Bird (1992), mengemukakan bahwa penyebab langsung terjadinya kecelakaan adalah perilaku dan kondisi yang tidak aman. Penyebab langsung timbul karena pengawasan yang jelek dari manajemen. Pengawasan merupakan hal yang sangat penting untuk jadi perhatian karena perilaku para tenaga kerja, sebab adanya pengawasan semata bukanlah sesuatu yang baik (Arianto, 2010). Pengawasan diperlukan untuk menegakkan peraturan keselamatan dan kesehatan kerja yang berlaku di tempat kerja. Menurut Green dalam Notoatmodjo (2010), pengawasan adalah salah satu faktor pendorong dalam pembentukan perilaku seseorang. Menurut Listyandini (2013), meskipun sudah terdapat 
peraturan keselamatan kerja yang mengikat, namun efek peraturan tersebut menjadi lemah apabila tidak dilengkapi dengan pengawasan yang baik. Halimah (2010), juga menyatakan bahwa peraturan keselamatan kerja hanya berupa tulisan sehingga dalam pelaksanaannya memerlukan pengawasan yang konsisten agar dapat meningkatkan kepatuhan terhadap peraturan. Pengawasan di tempat kerja dilakukan untuk mencegah terjadinya kecelakaan.

Dengan demikian, manajemen mempunyai kewajiban untuk melakukan pengawasan keselamatan dan kesehatan kerja di tempat kerja agar terhindar dari terjadinya kecelakaan kerja (Suma'mur, 1996). Berdasarkan konsep ILCI, pengawasan merupakan salah satu kontrol manajemen. Lack of control dalam konsep ILCI merupakan faktor penyebab kecelakaan, sehingga pengawasan keselamatan dan kesehatan kerja harus ditingkatkan agar tidak terjadi kecelakaan kerja yang dapat merugikan perusahaan baik materi maupun non materi. Bird dan Germain (1992), menyatakan bahwa tenaga kerja baru perlu mendapatkan perhatian yang lebih, pengawasan, pelatihan dan arahan dari rekan kerja dan pihak manajemen untuk membentuk kebiasaan yang dapat memengaruhi perilaku tenaga kerja saat bekerja.

Notoatmodjo (2003), menyatakan bahwa salah satu strategi dalam menciptakan perubahan perilaku yaitu dengan menggunakan kekuasaan dan kekuatan, misalnya dengan dibentuknya kebijakan dan peraturan serta perundang-undangan yang menuntut wajib dipatuhi oleh tenaga kerja. Cara ini dapat menghasilkan perubahan perilaku dengan cepat, namun perubahan tersebut belum tentu akan dapat berlangsung lama selama perubahan tersebut tidak didasari oleh kesadaran dan kemauan diri sendiri.

Menurut Utommi dalam Halimah (2010), pengawasan bertujuan untuk memberikan motivasi tenaga kerja agar bekerja dengan benar dan memastikan tenaga kerja tahu bagaimana melakukan pekerjaannya. Motivasi merupakan dorongan dari dalam diri seseorang untuk melakukan kegiatan tertentu (Notoatmodjo, 2010). Menurut Winardi (2002), motivasi adalah sejumlah proses yang dapat menyebabkan timbulnya sikap antusiasme dan persistensi dalam melaksanakan kegiatan. Motivasi akan membentuk sikap seseorang termasuk unsafe action.

\section{SIMPULAN}

Berdasarkan hasil penelitian di PT Pelabuhan Indonesia III Cabang Tanjung Perak, maka didapatkan hasil yaitu sebagian besar Tenaga Kerja Bongkar Muat (TKBM) berusia antara 31-40 tahun, memiliki masa kerja lebih dari 10 tahun, memiliki tingkat pendidikan SD, dan sebanyak 48 responden berpendapat bahwa tingkat pengawasan $\mathrm{K} 3$ cukup baik. Faktor individu yang memiliki hubungan yang signifikan dengan unsafe action adalah usia. Koefisien korelasi antara usia dan unsafe action adalah cukup. Tingkat pengawasan keselamatan dan kesehatan kerja dalam penelitian ini dikategorikan menjadi tiga, yaitu baik, cukup baik dan kurang baik. Dapat diketahui sebagian besar responden berpendapat bahwa variasi tingkat pengawasan K3 dapat dikatakan cukup baik. Hasil penelitian menyatakan bahwa terdapat hubungan yang signifikan antara pengawasan $\mathrm{K} 3$ dan unsafe action dan koefisien koeralasinya lemah.

\section{DAFTAR PUSTAKA}

Anizar. 2009. Teknik Keselamatan dan Kesehatan Kerja di Industri. Yogyakarta: Graha Ilmu.

Arianto, W. 2010. Faktor-faktor yang Berhubungan dengan Perilaku Penggunaan Alat Pelindung Diri di Areal Pertambangan PT Antam tbk Unit Bisnis Pertambangan Emas Pongkor Kabupaten Bogor. Tugas Akhir. Jakarta: Universitas Islam Negeri Syarif Hidayatullah. 
Badan Pembinaan Konstruksi dan Sumber Daya Manusia (BPKSDM). 2007. Laporan Tahunan Tahun 2006. Jakarta: Dinas Pekerjaan Umum.

Bird, E. F., Germain, L. 1992. Practical Loss Control Leadership, Edisi Revisi. USA: Division of International Loss Control Institute.

Geller, E. S. 2001. The Psychology of Safety Handbook. USA: Lewis Publisher.

Halimah, S. 2010. Faktor-faktor yang Memengaruhi Perilaku Aman Karyawan di PT Sim Plant Tambun II Tahun 2010. Skripsi. Jakarta: UIN.

Listiyandini, R. 2013. Analisis Faktor yang Berhubungan dengan Perilaku tidak Aman pada Pekerja Kontraktor di PT. X. Skripsi. Surabaya: Universitas Airlangga.

Notoatmodjo, S. 2003. Dasar-Dasar Pendidikan dan Pelatihan. Jakarta: Universitas Indonesia.

Notoatmodjo, S. 2003. Pendidikan dan Perilaku Kesehatan. Jakarta: Rineka Cipta.

Palin, P. 2012. Faktor yang Berhubungan dengan Kejadian Kecelakaan Kerja pada Karyawan Percetakan Sektor Informal Kelurahan Ballaparang Kecamatan Rappocini Makassar Tahun 2012. Jurnal Kesehatan. Makasar: Universitas Hasanuddin.

Permana, A. S. 2014. Hubungan Personal Factor dengan Unsafe Action Proses Pemasangan Pipa Baja oleh PT. Putra Negara Surabaya. Jurnal. Surabaya, ADLN Perpustakaan Universitas Airlangga.

Pracinasari, I. 2014. Penerapan Behavior Based Safety pada Pekerja di Divisi Steel Tower PT Bukaka Teknik Utama Tbk Tahun 2009. Skripsi. Surakarta: Universitas Sebelas Maret.

Pratiwi S. D. 2009. Tinjauan Faktor Perilaku Kerja Tidak Aman pada Pekerja Konstruksi Bagian Finishing Fasilitas dan Sarana Gelanggang Olahraga (GOR) Boker, Cilacas, Jakarta Timur 2009. Skripsi. Depok: Universitas Indonesia.
Rais, M., Nugraha, P. P., Baju, W. 2009. Kajian Pengaruh Predisposing, Enabling dan Reinforcing Factors terhadap Praktek Kerja Tenaga Kerja Bongkar Muat yang Berisiko Terjadinya Kecelakaan Kerja di Pelabuhan Tanjung Emas Semarang. Jurnal Promosi Kesehatan Indonesia.

Robbins, S.P. 2001. Perilaku Organisasi: Konsep, Kontroversi dan Aplikasi Jilid 1 (Edisi bahasa Indonesia).Jakarta:PT Prenhallind.

Salawati, L. 2009. Hubungan Perilaku, Manajemen Keselamatan dan Kesehatan Kerja dengan Terjadinya Kecelakaan Kerja di Laboratorium Patologi Klinik Rumah Sakit DR. Zainoel Abidin Banda Aceh Tahun 2009. Tesis. Sumatra: Sekolah Pascasarjana Universitas Sumatra Utara Medan.

Sarwono, S.W. 1997. Psikologi Sosial; Psikologi Kelompok dan Psikologi Terapan. Jakarta: Balai Pustaka

Setyawati. 2010. Pengantar Kesehatan dan Keselamatan Kerja di Perusahaan. Jakarta: Fakultas Kesehatan Masyarakat Universitas Indonesia Press.

Shiddiq, S. Wahyu, A. Muis, M. 2013. Hubungan Persepsi K3 Karyawan Dengan Perilaku Tidak Aman Di Bagian Produksi Unit IV PT. Semen Tonasa Tahun 2013. Media Kesehatan Masyarakat Indonesia Volume 10 Nomor 2. Makassar: Universitas Hasanuddin Makassar.

Sholehudin, M. 2013. Hubungan Personal Factor dengan Unsafe Action di Unit X- PT. Baja X. Jurnal. Surabaya: ADLN Perpustakaan Universitas Airlangga.

Sirait, G. B. 2011. Analisis Perilaku Berisiko Pada Pekerja Pengelasan Di Jalan Mahkamah Medan Tahun 2011. Skripsi. Medan: Universitas Sumatera Utara.

Sulfikar, S. 2015. Analisis Faktor yang Berhubungan dengan perilaku Keselamatan (Safety Behavior). Tesis. Surabaya: Universitas Airlangga.

Suma'mur, P. K. 1996. Ergonomi untuk Produktivitas Kerja. Jakarta: CV. Haji Masagung. 
Suma'mur, P. K. 2009. Higiene Perusahaan dan Kesehatan Kerja. Jakarta: PT. Toko Gunung Agung. Cetakan XII.

Suryanto, D. I. D. 2017. Hubungan Kebijakan K3 dan Pengawasan K3 dengan Unsafe Action TKBM. Skripsi. Surabaya: Universitas Airlangga.
Undang-Undang Republik Indonesia Nomor 17 Tahun 2008 Tentang Pelayaran. Jakarta.

Winarsunu, T. 2008. Psikologi Keselamatan Kerja. UMM Press, Malang. 